\title{
Les Cent Nouvelles nouvelles présentées par Roger Dubuis
}

\section{Paola Cifarelli}

\section{Q OpenEdition \\ 1 Journals}

\section{Edizione digitale}

URL: http://journals.openedition.org/studifrancesi/27286

DOI: 10.4000/studifrancesi.27286

ISSN: 2421-5856

\section{Editore}

Rosenberg \& Sellier

\section{Edizione cartacea}

Data di pubblicazione: 31 décembre 2006

Paginazione: 583

ISSN: 0039-2944

\section{Notizia bibliografica digitale}

Paola Cifarelli, «Les Cent Nouvelles nouvelles présentées par Roger Dubuis », Studi Francesi [Online], 150 (L | III) | 2006, online dal 30 novembre 2015, consultato il 08 novembre 2020. URL : http:// journals.openedition.org/studifrancesi/27286; DOI : https://doi.org/10.4000/studifrancesi.27286

Questo documento è stato generato automaticamente il 8 novembre 2020.

\section{(c) (i) (9)}

Studi Francesi è distribuita con Licenza Creative Commons Attribuzione - Non commerciale - Non opere derivate 4.0 Internazionale. 


\title{
Les Cent Nouvelles nouvelles présentées par Roger Dubuis
}

\author{
Paola Cifarelli
}

\section{NOTIZIA}

Les Cent Nouvelles nouvelles présentées par Roger DUBUIS, Paris, Champion, 2005

(«Traductions des classiques du Moyen Age», 69), pp. 570.

1 La collezione delle "Traductions des classiques du Moyen Age" si arricchisce della versione in francese moderno delle Cent Nouvelles nouvelles che R. Dubuis, eminente specialista della novellistica in mediofrancese, realizzò una quindicina d'anni or sono sulla base dell'edizione critica di F. P. Sweetser (1966), e pubblicò a Lione per le Presses Universitaires nel 1991. Riproponendo al pubblico questo lavoro, l'A. intende promuovere la conoscenza diretta di un testo spesso citato ma poco letto: sopprimere "l'obstacle de la langue" significa infatti ridurre le difficoltà del lettore moderno nell'approccio ad un'opera che ha esercitato un ruolo chiave nel panorama della letteratura quattrocentesca.

2 Nella Prefazione, l'A. riesce nell'intento di coniugare una solida base scientifica ad uno stile divulgativo unendo sinteticità, chiarezza e spigliatezza. Dopo aver evidenziato i rapporti tra le Cent Nouvelles nouvelles e le altre raccolte coeve (tra cui quella di Philippe de Vigneulles e la traduzione del Decameron), lo studioso schizza la storia di questo genere breve ai suoi albori e ripercorre le tappe della critica moderna, spesso poco generosa nei confronti di questo testo in particolare. Vengono poi affrontate le questioni relative allo statuto dell'acteur, alla veridicità della cornice nella quale si inseriscono i racconti, al ruolo del committente intradiegetico e alla definizione, ancora problematica, della novella. Il giudizio critico sul valore del testo si sofferma in particolare sul modo di intendere riso e comicità nel tardo medioevo e sull'attualità di alcune tematiche, nonostante gli indubbi mutamenti del gusto. 
3 Alla traduzione in francese moderno, fedele allo spirito del testo più che alla sua lettura erudita, seguono un indice dei nomi e, soprattutto, un'utilissima sezione bibliografica, che conferisce ulteriore spessore scientifico a questo lavoro: il lettore vi troverà le indicazioni sulla tradizione manoscritta e a stampa del testo fino alle edizioni più recenti, oltre all'indicazione delle diverse traduzioni antiche e moderne in altre lingue e all'indicazione degli studi critici sull'opera. 